\title{
AMMONIA REMOVAL FROM FERTILIZER PLANT EFFLUENTS BY A COUPLED ELECTROSTATIC SHIELDING BASED ELECTRODIALYSIS I ELECTRODEIONIZATION PROCESS
}

\section{K. DERMENTZIS * \\ A. DAVIDIS \\ C. CHATZICHRISTOU \\ A. DERMENTZI}

Received: $27 / 01 / 10$

Accepted: 07/12/11

\author{
Technological Education Institute (TEI) \\ of Kavala, Department of Engineering Science \\ Laboratory of Chemical Technology and Electrochemistry \\ 65404 Agios Loucas, Kavala, Hellas
}

\section{ABSTRACT}

Electrically and ionically conducting graphite powder beds interposed between the anode and cathode inside an electrolytic setup are used as intermediate bipolar electrodes. The beds cause electric field discontinuity by eliminating the applied electric field locally within their mass and act as electrostatically shielded zones - ion and ionic current sinks and thus ion concentrating compartments, whereas the adjacent compartments become ion depleting compartments. The ion sinks were implemented in a coupled electrostatic shielding electrodialysis/electrodeionization process to remove ammonium nitrate from fertilizer plant wastewaters. The batch wise operated electrostatic shielding electrodialysis of a solution containing $1310 \mathrm{mg} \mathrm{L}^{-1}$ ammonium nitrate produced in $28 \mathrm{~min}$ at a current density of $15-30 \mathrm{~A} \mathrm{~m}^{-2}$ a concentrate ammonium nitrate solution which could be recycled to the fertilizer plant unit and a diluate containing $50 \mathrm{mg} \mathrm{L}^{-1}$ ammonium nitrate. The diluate was subsequently used as feed in the electrostatic shielding electrodeionization process to produce pure water of a $\mathrm{NH}_{4}{ }^{+}$and $\mathrm{NO}_{3}{ }^{-}$ion concentration of less than $1 \mathrm{mg} \mathrm{L}^{-1}$ respectively with a flow rate of $5.51 \times 10^{-4} \mathrm{dm}^{3} \mathrm{~s}^{-1}$ and a current density of $50 \mathrm{~A} \mathrm{~m}^{-2}$.

KEYWORDS: Ammomium nitrate, Faraday cage, ion sink, ionic current sink-source, membrane free electrodeionization.

\section{INTRODUCTION}

Ammonia contamination of natural water is an increasing environmental problem. Ammonia waste waters are generated in agricultural livestock farming and industrial processes, such as surface finishing, electroplating, nuclear fuel cycle, acrylonitrile synthesis and synthetic fertilizer production. It is well known that ammonia causes eutrophication which is fatal to aquatic life and a hindrance to the disinfection of water supplies. Furthermore, ammonia emits an offensive smell and causes carcinogenesis. Processes applied for removal of ammonia from industrial wastewaters are: air stripping (Cheung et al.,1997), ion exchange (Jorgensen and Weatherley, 2003; Lin and Wu, 1996; Du et al., 2005), biological processes (Koren et al., 2000; Chen et al., 2005), reverse osmosis (Bodalo et al., 2005; Karabelas et al., 2001), electrochemical oxidation (Cabeza et al., 2007; Li and Liu, 2009; Kim et al., 2006; Li et al., 2009; Lopez de Mishima et al., 1998) and electrodeionization.

Electrodeionization is the removal of ions and ionizable species from water or organic liquids. It uses electrically active media and an electrical potential to cause ion transport and may be operated batch wise, or continuously. Continuous electrodeionization processes such as electrodialysis (Gain et al., 2002; Yang et al., 2008; Mondor et al., 2008) and filled cell electrodialysis or otherwise called continuous electrodeionization (Spiegel et al., 1999) comprise alternating permselective cation exchange membranes and anion exchange membranes, which under the influence of the electric field allow only cations or only anions respectively to permeate their mass and simultaneously retain coions so that diluate and concentrate compartments are created and deionization occurs. 
Membrane electrodeionization processes exhibit the known limitations associated with membranes, such as membrane fouling, scaling and concentration polarization.

Batch electrodeionization processes such as capacitive deionization are collection / discharge processes which rely on the formation of double-layer supercapacitor at the solution/electrode interface and need electrodes with very large specific areas, such as nano-structured activated carbon aerogels (Gabelich et al., 2002; Zou et al., 2008).

In our previous works (Dermentzis, 2008, 2010) it was shown that electrostatic shielding based electrodialysis/electrodeionization can be realized by means of electrostatic shielding zones-ionic current sinks ESZs-ICSs instead of permselective ion exchange membranes. The ESZs-ICSs are formed by electronically and ionically conducting media e.g. graphite powder packed beds interposed between the anode and cathode which cause electric field discontinuity inside the electrolytic setup resulting in ion diluting and ion concentrating compartments.

The present paper discusses a new alternative way of a membrane free electrodialysis/electrodeionization process for removal of $\mathrm{NH}_{4}{ }^{+}$and $\mathrm{NO}_{3}{ }^{-}$ions from water solutions or industrial effluents such as fertilizer plant wastewaters.

The proposed new process differs from classical electrodialysis-continuous electrodeionization processes in that it does not use any permselective ion exchange membranes and therefore it does not exhibit the above mentioned membrane associated limitations. It also differs from classical batch wise operated capacitive deionization in that it is a continuous process i.e. diluate and concentrate are received from separate and unchanged compartments without any removal of diluate and concentrate or any down time for electrode saturation, regeneration and rinsing steps.

Ammonia contaminated industrial effluent streams originate from ammonium nitrate fertilizer production units through wet scrubbing of ammonia vapours in a packed column with nitric acid (Bodalo et al., 2005; Alexiou et al., 2006). These effluent streams may contain 200-500 ppm total nitrogen as $\mathrm{N}-\mathrm{NH}_{3}$ and $\mathrm{N}-\mathrm{NO}_{3}{ }^{-}$. They are acidic $(\mathrm{pH}=1-2)$ and hot $\left(\sim 70^{\circ} \mathrm{C}\right)$. Therefore, they should be appropriately treated before being discharged to the environment.

Electrodeionization is an emerging environmental green technology (Masri and Therkelsen, 2003). Its target is to separate the effluent stream into a small-volume concentrate of ammonium nitrate that can be recycled to the fertilizer production unit and into a low-TDS diluate (electrodialysis) or into pure deionized water (electrodeionization). In this way, a closed-loop process with water and materials recycling and no liquid discharge to the environment would be achieved.

\section{METHODS}

We used the self-made electrochemical setup (Figure1 and Figure 2) as described in our previous work (Dermentzis, 2010). The terminal electrodes are platinized titanium grids (TiTaN, Titanium Tantalum Products Limited, India). The bipolar intermediate electrodes are packed beds of graphite powder (Merck, particle size $<50 \mu \mathrm{m}$, electrical conductivity $2 \times 10^{4} \mathrm{~S} \mathrm{~m}^{-2}$ ) or powdered electrode graphite (Figure 1) which is used as anode by the electrolytic production of aluminium (Aluminium of Greece, particle size $<1 \mathrm{~mm}$, electrical conductivity $3.3 \times 10^{4} \mathrm{~S} \mathrm{~m}^{-2}$ ). Anode graphite is preferable because of its better electrical and electrocatalytic properties. Polypropylene separators $S$ (Celgard 3407) were used to separate the different cell compartments.

The electrodialysis cell illustrated in Figure 1 contains four ICSs serving as ion traps and ion concentrating compartments, three diluate compartments between them and two electrode compartments, all placed in parallel. Each compartment is $15 \mathrm{~cm}$ long and $12 \mathrm{~cm}$ wide. The ICSs have a thickness of $5 \mathrm{~mm}$ and an effective area of $150 \mathrm{~cm}^{2}$ each. The area of each ICS is equal to the vertical cross-section area of the electrolytic cell. All compartments are separated from each other by the separators S. The distance between two successive ICSs and also between the ICS and the adjacent end-electrode is $5 \mathrm{~mm}$ and is determined by the ion conducting separators and spacers. 

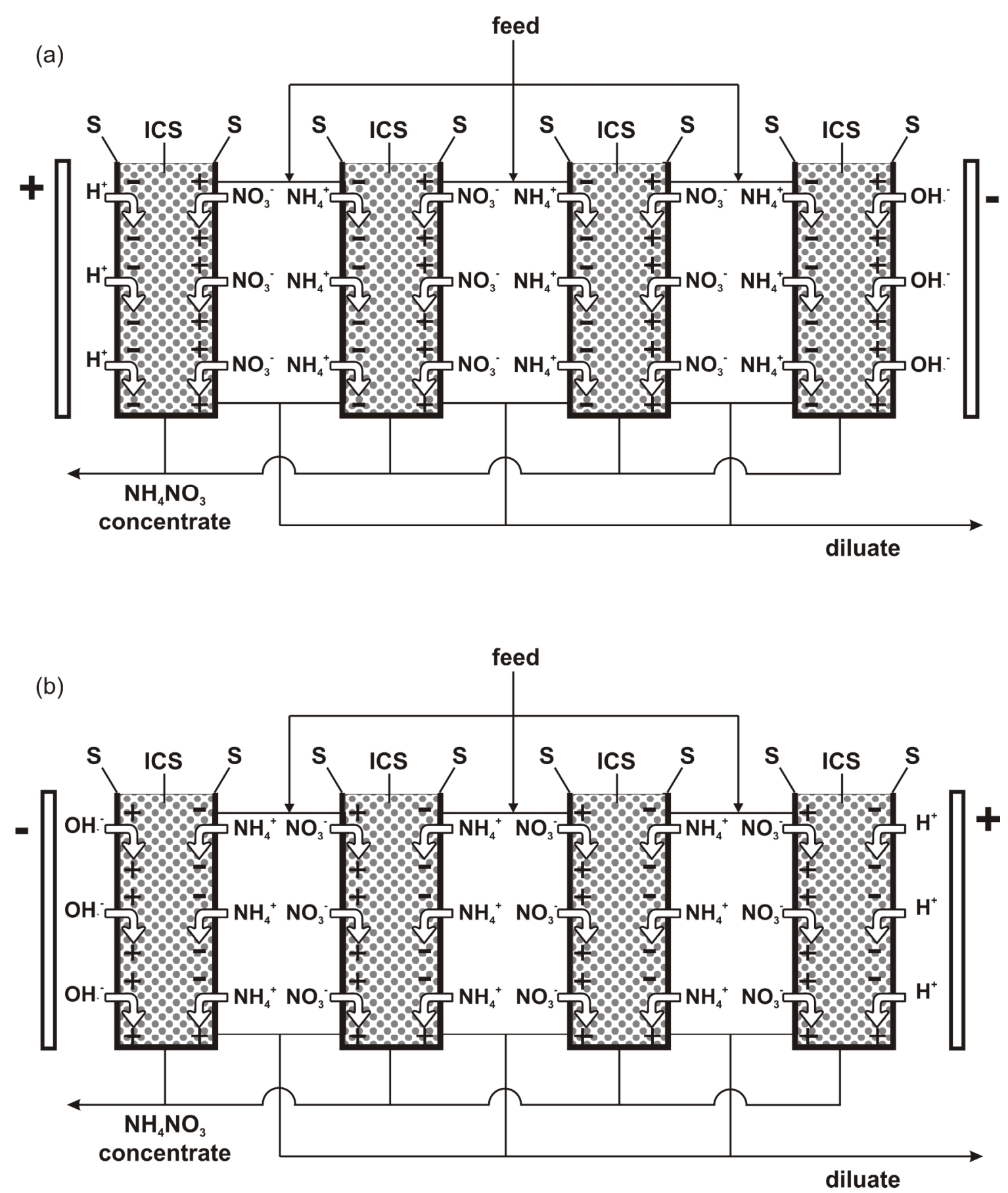

Figure 1. (a) Schematic diagram of the electrostatic shielding electrodialysis setup for removal of $\mathrm{NH}_{4} \mathrm{NO}_{3}$ from fertilizer plant effluent streams. $\mathrm{NH}_{4}{ }^{+}$and $\mathrm{NO}_{3}{ }^{-}$ions accumulate inside the electrostatically shielded ICSs. (b) By reversing the cell polarity the deionization process is continued and only the direction of the accumulated ions is reversed

The separators are sealed so that the different compartments do not communicate hydraulically with each other but only electrically (ionically) through the electric field. Each ICS has a bipolar function and belongs simultaneously to two adjacent diluate compartments as in bipolar electrochemical double layer supercapacitors.

The three diluate compartments are filled with the feed solution. The anode compartment is filled with a $0.05 \mathrm{M} \mathrm{H}_{2} \mathrm{SO}_{4}$, the cathode with a $0.05 \mathrm{M} \mathrm{NaOH}$ solution, while the four concentrate compartments ICSs are filled with electrode graphite powder, are only intermittently rinsed (once an hour or seldomer) with the feed solution and are steadily let to drain. 
The graphite powder was activated by treating it in a $1 \mathrm{M} \mathrm{NaOH}$ solution at $90^{\circ} \mathrm{C}$ for three hours. To complete physical absorption of $\mathrm{NH}_{4} \mathrm{NO}_{3}$ in graphite, the ICSs were rinsed with a $0.1 \mathrm{M} \mathrm{NH}_{4} \mathrm{NO}_{3}$ solution until saturation and then with deionized water.

Figure 2 represents a filled cell electrodialysis or electrodeionization cell which in principle is the same as Figure 1, with the only difference that separated bed resins, e.g. cation exchange resin CR and anion exchange resin AR are placed inside the diluate compartments of Figure 1. Feed water to be deionized permeates first the $\mathrm{CR}$ and then the AR resin.

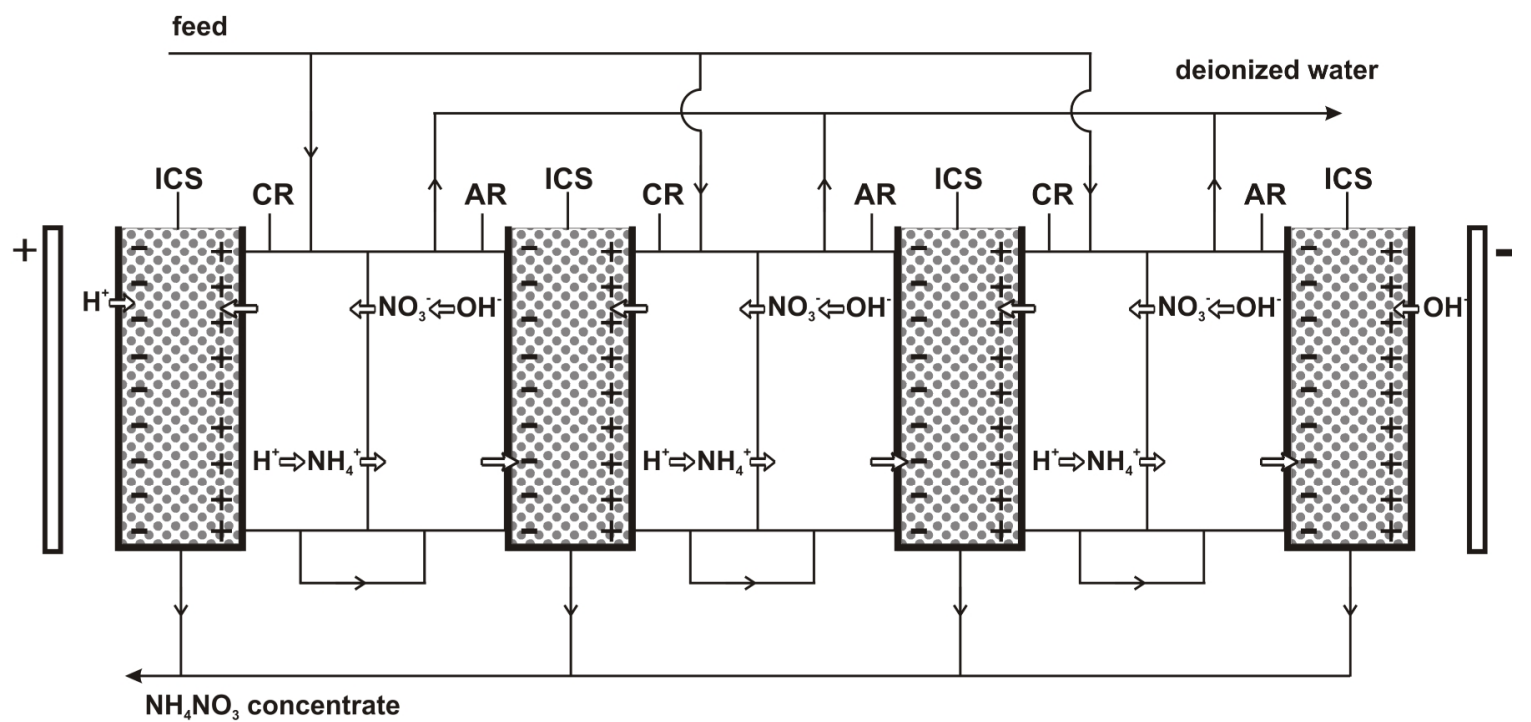

Figure 2. Schematic diagram of the electrostatic shielding electrodeionization setup

for removal of $\mathrm{NH}_{4} \mathrm{NO}_{3}$ and pure water production with simultaneous regeneration of the separated ion exchange resin beds. Feed water is passed first through the CR and then through the AR resin bed to be deionized

The $C R$ and $A R$ resins were pretreated and immersed in $0.1 \mathrm{M} \mathrm{NH}_{4} \mathrm{NO}_{3}$ solutions respectively for 3 days, then packed into the corresponding CR-loaded and AR-loaded compartments and rinsed with deionized water. The anode and the cathode compartments were filled with $0.05 \mathrm{M} \mathrm{H}_{2} \mathrm{SO}_{4}$ and $0.05 \mathrm{M}$ $\mathrm{NaOH}$ solutions respectively as in figure 1.

The concentrations of $\mathrm{NH}_{4}{ }^{+}$and $\mathrm{NO}_{3}{ }^{-}$ions in water were investigated spectrophotometrically (Hitachi U-2000). A power supply (STELL TRAFO / POWER SUPPLY, PHYWE Systeme GmbH \& Co. KG, Germany) was used to maintain constant DC voltage or constant DC current. Voltage and current were measured by a multimeter (PHYWE).

$\mathrm{H}_{2} \mathrm{SO}_{4}$ and $\mathrm{NaOH}$ were of analytical grade (Merck). The ion exchange resins used were strongly cation exchanger $\mathrm{H}^{+}$- form (Amberlite IR-120, Merck) with an ion exchange capacity of $1.7 \mathrm{mmol} \mathrm{ml} \mathrm{ml}^{-1}$ and strongly basic anion exchanger $\mathrm{OH}^{-}$- form (Merck) with an ion exchange capacity of $1.45 \mathrm{mmol} \mathrm{ml}^{-1}$.

\section{RESULTS AND DISCUSSION}

\subsection{Electrostatically shielded ion concentrating compartments - ESZs, ICSs}

Current sinks and sources are local currents from a location where they can be detected into a location they can not be detected (current sink) or vice versa (current source). However, all known current sinks are related to electronic current sinks (ECSs). As far as we are aware no other paper except for our previous works appeared in literature dealing with ICSs and electrostatic shielding based electrodialysis/electrodeionization processes.

It is known from electric field theory and Faraday cage (Purcell, 1965) and our previous works that, when a conductor is placed inside an electric field, an opposite field is formed so that the original electric field in the interior of the conductor is canceled. The field intensity inside the conductor is zero and its whole space is electrostatically shielded independent on the external field intensity (Faraday cage). Therefore, an abrupt potential jump is formed between the inside and the outside of the conductor. Since in an electrolytic or an electrodialysis cell ion migration is caused by the applied 
electric field, it will stop within an electronically and ionically conducting ICS of zero field, interposed between the anode and cathode.

The ESZs become ion concentrating compartments while the adjacent compartments become ion diluting compartments. The ESZ acts here as a "sink" for ions and ionic currents (ICS). The ionic current (real direction) is eliminated at the cathodically polarized side of the ICS (current sink) and appears again at its anodically polarized side (current source). The terms "ion sink", "ionic current sink-source", membrane-less or electrostatic shielding electrodialysis/electrodeionization were introduced in literature for electrochemical applications first with our works.

$\mathrm{NH}_{4}{ }^{+}$and $\mathrm{NO}_{3}{ }^{-}$ions can move inside the ICS but only by diffusion and convection and not in field direction. The concentrate compartment ICS is never saturated with the accumulated ions. Because of the electric field its two short-circuited sides become polarized and saturated with oppositely charged ions but at the same time they are discharged and release the same ions because of shorting.

The thickness of the ICS plays a significant role for purification, regarding the electron transfer redox reactions between the two polarized sides of each ICS inside the electric field. The thicker the ICS the higher the potential difference between its two polarized sides inside a given electric field. If this potential difference exceeds the electrochemical decomposition potential of water or other solutes, electron transfer redox reactions occur between the two polarized sides of the ICS. This phenomenon does not contribute to deionization but to aimless electrical energy consumption and should be avoided by reducing the ICS thickness. Also the current density can be considerably increased by using thinner ICSs.

We can take advantage of these useful new findings and drive ions inside the ICSs, create ion concentrating and ion depleting compartments and perform in this way membrane free electrodialysis and electrodeionization of water and industrial effluents.

\subsection{Electrostatic shielding electrodialysis of fertilizer plant wastewaters}

We first raised $\mathrm{pH}$ of the acidic fertilizer plant effluent by adding ammonia until it reached $\mathrm{pH} \sim 5$. This almost stoichiometric $\mathrm{NH}_{4} \mathrm{NO}_{3}$ solution after $\mathrm{pH}$ adjustment containing $300 \mathrm{ppm} \mathrm{NH}_{4}^{+}$and $1010 \mathrm{ppm} \mathrm{NO}{ }_{3}^{-}$was placed in the three diluate compartments of the cell illustrated in Figure 1 for electrodialytic treatment. The proposed new electrostatic shielding electrodialysis cell with ICSs instead of ion exchange membranes has proved to be efficient for the removal of ions such as $\mathrm{NH}_{4}{ }^{+}$ and $\mathrm{NO}_{3}{ }^{-}$.

The electrodialysis process was conducted batch wise under constant voltage and decreasing current at a current density of $15-30 \mathrm{~A} \mathrm{~m}^{-2} . \mathrm{NH}_{4}{ }^{+}$and $\mathrm{NO}_{3}{ }^{-}$ions moving towards the cathode and anode respectively permeate the ICSs and due to the local elimination of the applied electric field inside the ICSs accumulate inside them. The accumulated $\mathrm{NH}_{4} \mathrm{NO}_{3}$ together with the osmotically and electroosmotically transported water molecules form a condensate which is received from the bottom of the two central ICSs (Figuer 1). In the left ICs the entering $\mathrm{NO}_{3}^{-}$ions and the formed $\mathrm{H}^{+}$ions from the anode form a $\mathrm{HNO}_{3}$ concentrate, while in the right ICS the entering $\mathrm{NH}_{4}^{+}$ions and the formed $\mathrm{OH}$ - ions from the cathode form a $\mathrm{NH}_{4} \mathrm{OH}$ concentrate. The $\mathrm{HNO}_{3}$ and $\mathrm{NH}_{4} \mathrm{OH}$ concentrates are mutually neutralized to $\mathrm{NH}_{4} \mathrm{NO}_{3}$ and mixed with the $\mathrm{NH}_{4} \mathrm{NO}_{3}$ concentrate received from the two central ICSs. Figure 3 shows the decrease of current and solution conductivity with time, due to the concentration decrease of $\mathrm{NH}_{4} \mathrm{NO}_{3}$ with time in the ion diluting compartments between the ICSs.

Figures 4 and 5 depict the corresponding concentration variations and percent removal of $\mathrm{NH}_{4}{ }^{+}$and $\mathrm{NO}_{3}{ }^{-}$ions versus time in the three diluting compartments. The removal rate is significant during the first $20 \mathrm{~min}$. and decreases sharply as electrodialysis is prolonged, due to the decrease of the solution concentration and therefore the increase of its resistance. At higher fields where the electrochemical decomposition potential of $\mathrm{H}_{2} \mathrm{O}$ or $\mathrm{NH}_{4} \mathrm{NO}_{3}$ can be exceeded, $\mathrm{H}^{+}$and $\mathrm{OH}^{-}$ions can also partially be electronated to pure $\mathrm{H}_{2}$ and $\mathrm{O}_{2}$ gases at the corresponding cathodically and anodically polarized polarized sides of the ICSs through electron transfer redox reactions. This phenomenon is unproductive energy consumption and should be avoided. 


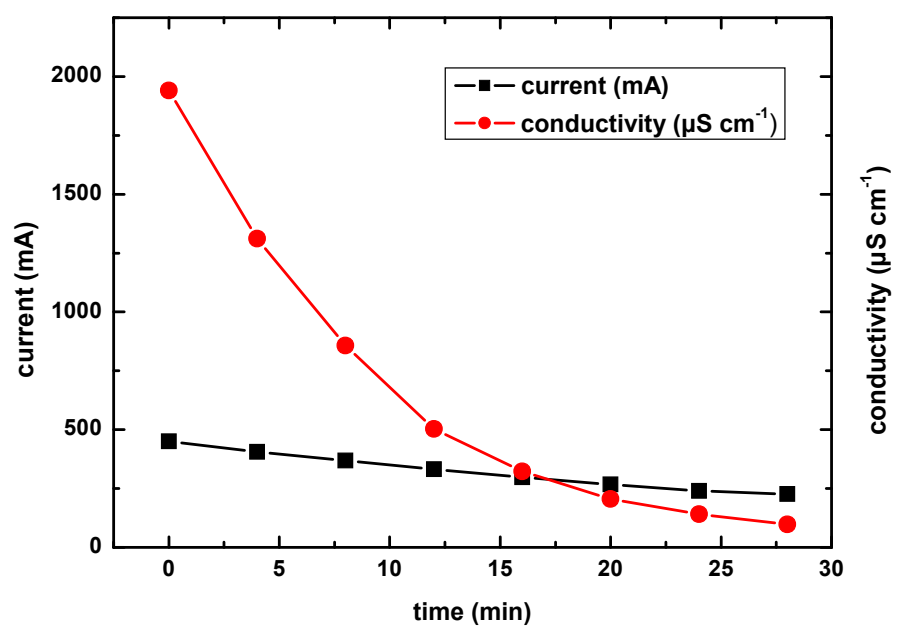

Figure 3. Current and conductivity variations with time during the electrostatic shielding electrodialysis of the $\mathrm{NH}_{4} \mathrm{NO}_{3}$ containing solution

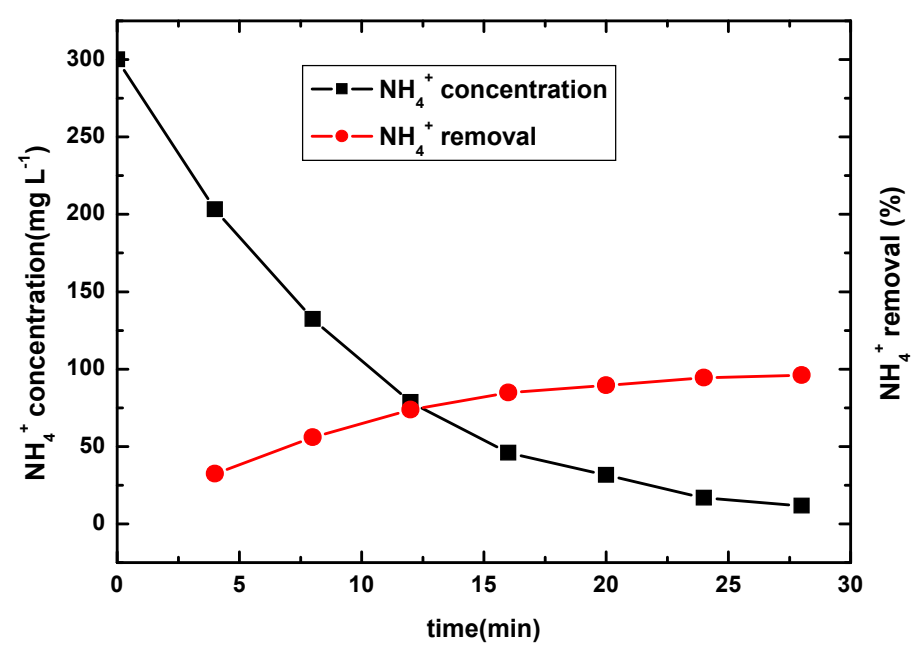

Figure 4. Concentration variation and percent removal of $\mathrm{NH}_{4}^{+}$ions in the diluate compartments during the batch wise operated electrostatic shielding electrodialysis of the fertilizer plant effluent stream

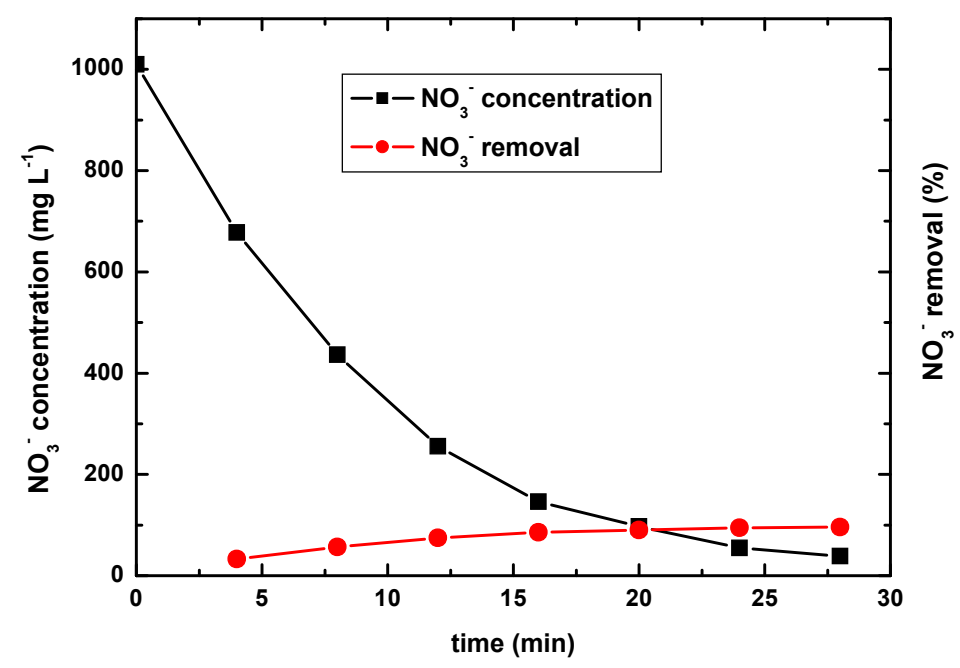

Figure 5. Concentration variation and percent removal of $\mathrm{NO}_{3}{ }^{-}$ions in the diluate compartments during the batch wise operated electrostatic shielding electrodialysis of the fertilizer plant effluent stream 
The $\mathrm{NH}_{4} \mathrm{NO}_{3}$ concentrate received from the ICSs may be recycled into the fertilizer production unit. The obtained diluate of low TDS can reduce the load of the ion exchange unit for production of boiler feed water or can be used as feed in the subsequent electrodeionization process (Figure 2) for production of deionized water as will be explained next in section 3.3. In this way, the process can save a lot of water resource and realize "zero pollution".

\subsection{Electrostatic shielding electrodeionization of diluted fertilizer plant wastewaters.}

Electrodeionization systems are commonly used for purification of solutions where the initial concentrations of ions are $<200 \mathrm{ppm}$. Thus, the $\mathrm{NH}_{4} \mathrm{NO}_{3}$ diluate obtained during the electrodialysis process (section 3.2) was subsequently passed as feed water through the cation $\mathrm{CR}$ and the anion AR exchange resin beds of the filled cell electrodeionization setup (Figure 2) for production of deionized water. Feed water permeates first the CR and then the AR resin to be deionized.

The generated $\mathrm{H}^{+}$ions in the anode compartment and the anodically polarized sides of the ICSs repell and replace the $\mathrm{NH}_{4}{ }^{+}$cations from the $\mathrm{CR}$ resin and the generated $\mathrm{OH}^{-}$ions in the cathode and the cathodically polarized sides of the ICSs repel and replace the $\mathrm{NO}_{3}{ }^{-}$anions from the AR resin beds. The replaced cations and anions together with the electroosmotically transported water molecules are transferred to the concentrate compartments (ICSs) where, due to electrostatic shielding, the electromigration of ions is stopped there and ions accumulate inside them. Deionized water can be produced with $\mathrm{NH}_{4}{ }^{+}$and $\mathrm{NO}_{3}^{-}$ion concentrations of less than $1 \mathrm{ppm}$ respectively in both modes, batch or continuous, while the resins were simultaneously regenerated without the use of any chemical regenerants. The product water quality stays constant over time, whereas in regenerable ion exchange with chemicals it degrades as the resins approach exhaustion. In the received concentrate $\mathrm{NH}_{4} \mathrm{NO}_{3}$ is concentrated to $1500 \mathrm{mg} \mathrm{L}^{-1}$ i.e. it is enriched by a factor of $\sim 30$ which can be recycled as feed water into the electrodialysis setup (Figure 1). The electrodeionization process was conducted in a continuous mode under constant current and increasing voltage at a current density of $50 \mathrm{~A} \mathrm{~m}^{-2}$.

The electrodialysis and electrodeionization processes were evaluated in terms of percent removal (pr) and enrichment factor (ef), which were calculated from the equations (1) and (2) respectively:

$$
\begin{aligned}
& p r=\frac{C_{o}-C}{C_{o}} \times 100 \\
& \text { ef }=\frac{C_{c}}{C_{o}}
\end{aligned}
$$

where $C_{o}$ and $C$ are the inlet and outlet concentrations in moles $\mathrm{L}^{-1}$ of $\mathrm{NH}_{4}{ }^{+} \mathrm{NO}_{3}{ }^{-}$or $\mathrm{NH}_{4} \mathrm{NO}_{3}$ in the diluate compartments and $\mathrm{C}_{c}$ in the concentrate compartments respectively. In the continuous mode of electrodeionization with a current density of $50 \mathrm{~A} \mathrm{~m}^{-2}$ the flow rate was $5.51 \times 10^{-4} \mathrm{dm}^{3} \mathrm{~s}^{-1}$ diluate stream.

\section{CONCLUSIONS}

Based on the experiments conducted in this study, the following conclusions can be drawn:

(1) Bipolar intermediate electrically and ionically conducting graphite powder bed electrodes eliminate the applied electric field locally inside their mass and can therefore serve as electrostatically shielded zones-ionic current sinks and ion concentrating compartments in membrane-less electrodialysis and electrodeionization applications.

(2) The current density can be enhanced by using thin electrostatic shielding zones - ionic current sinks and therefore avoiding the electron transfer redox reactions.

(3) The proposed new electrodialysis/electrodeionization cells do not exhibit the known membrane associated limitations such as membrane fouling, scaling and concentration polarization.

(4) A membrane-less electrostatic shielding electrodialysis cell was implemented in a batch wise purification of a fertilizer plant waste water containing $300 \mathrm{mg} \mathrm{L}^{-1} \mathrm{NH}_{4}^{+}$and $1010 \mathrm{mg} \mathrm{L}^{-1} \mathrm{NO}_{3}^{-}$ under constant voltage and decreasing current at a current density of $15-30 \mathrm{~A} \mathrm{~m}^{-2}$. The concentrations of $\mathrm{NH}_{4}{ }^{+}$and $\mathrm{NO}_{3}{ }^{-}$ions decreased with time and fell to 11.6 and $38.4 \mathrm{mg} \mathrm{L}^{-1}$ respectively in 28 min., while a $\mathrm{NH} 4 \mathrm{NO} 3$ concentrate built up inside the concentrating 
compartments (ICSs). Subsequently, a membrane-less electrostatic shielding electrodeionization cell was used for a continuous purification of the diluate obtained from the former electrodialysis process producing pure water with a $\mathrm{NH}_{4}{ }^{+}$and $\mathrm{NO}_{3}{ }^{-}$ion concentration $>1 \mathrm{mg} \mathrm{L}^{-1}$ respectively at a flow rate of $5.51 \times 10^{-4} \mathrm{dm}^{3} \mathrm{~s}^{-1}$ diluate stream and a current density of $50 \mathrm{~A} \mathrm{~m}^{-2}$.

\section{REFERENCES}

Alexiou S.D., Vasiliadis K., Christoforidis A., Karageorgos E. and Rapsomanikis S., (2006) Source Apportionment of inorganic particulate matter in an industrial atmospheric environment near Kavala, Greece, Conf. Proc. Protection and Restoration of the Environment, Chania, Greece.

Bodalo A., Gomez J.L., Gomez E., Leon G. and Tejera M., (2005), Ammonium removal from aqueous solutions by reverse osmosis using acetate membranes, Desalination, 184, 149-155.

Cabeza A., Urtiaga A., Rivero M.-J. and Ortiz I., (2007), Ammonium removal from landfill leachate by anodic oxidation, J. Hazard. Mater., 144, 715-719.

Chen Y.-X., Yin J. and Wang K.-X., (2005), Long-term operation of biofilters for biological removal of ammonia, Chemosphere, 58, 1023-1030.

Cheung K.C., Chu L.M.and Wong M.H., (1997), Ammonia stripping as a pretreatment for landfill leachate, Water, Air, \& Soil Pollution, 94, 209-220.

Dermentzis K., (2008), Continuous electrodeionization through electrostatic shielding, Electrochim. Acta, 53, 2953-2962.

Dermentzis K., (2010), Removal of nickel from electroplating rinse waters using Electrostatic shielding electrodialysis/electrodeionization, J. Hazard. Mater., 173, 647 - 652.

Du Q., Lin S., Cao Z. and Wang Y., (2005), Ammonia removal from aqueous solution using natural chinese clinoptilolite, Sep. Purif. Technol., 44, 229-234.

Gabelich C.J., Tran T.D. and Mel Suffet I.H. (2002) Electrosorption of inorganic salts from aqueous solutions ysing carbon aerogels, Environ. Sci. Technol., 36, 3010-3019.

Gain E., Laborie S., Viers Ph., Rakib M., Durand G. and Hartmann D., (2002), Ammonium nitrate wastewater treatment by coupled membrane electrolysis and electrodialysis, J. Appl. Electrochem., 32, 969-975.

Jorgensen T.C. and Weatherley L.R., (2003), Ammonia removal from wastewater by ion exchange in the presence of organic contaminants, Water Res., 37, 1723-1728.

Karabelas A.J., Yiantsios S.G., Metaxiotou Z., Andritsos N., Akiskalos A., Vlachopoulos G. and Stavroulias S., (2001), Water and materials recovery from fertilizer industry acidic effluents by membrane processes, Desalination, 138, 93-102.

Kim K.-W., Kim Y.-J., IKim.-T., Park G.-I. and Lee E.-H., (2006), Electrochemical conversion characteristics of ammonia to nitrogen, Water Res., 40, 1431-1441.

Koren D.W., Gould W.D. and Bedard P., (2000), Biological removal of ammonia and nitrate from simulated mine and mill effluents, Hydrometallurgy, 56, 127-144.

Li L., Liu Y., (2009), Ammonia removal in electrochemical oxidation: Mechanism and pseudo-kinetics, J. Hazard. Mater. 161 1010-1016.

Li M., Feng C., Zhang Z., Zhao R., Lei X., Chen R. and Sugiura N., (2009) Application of an electrochemical-ion exchange reactor for ammonia removal, Electrochim. Acta, 55, 159-164.

Lin S.H. and Wu C.L., (1996), Ammonia removal from aqueous solution by ion exchange, Ind. Eng. Chem. Res., 35, 553-558.

Lopez de Mishima B.A., Lescano D., Holgado T. M. and Mishima H.T., (1998), Electrochemical oxidation of ammonia in alkaline solutions: its applications to an amperometric sensor, Electrochim. Acta, $\mathbf{4 3}$ 395-404.

Masri M. and Therkelsen R., (2003), Emerging Environmental Technologies: An Analysis of New Treatment Technologies for the California Energy Commission, Rep.No.1007411 EPRI, Palo Alto CA.

Mondor M., Masse L., Ippersiel D., Lamarche F. and Masse D.I., (2008) Use of electrodialysis and reverse osmosis for the recovery and concentration of ammonia from swine manure, Bioresource Technol., 99, 7363-7368.

Purcell E.M. (1965), Faraday cage, In: Electricity and Magnetism, Berkeley Physics Cource, (Eds.), Mc Graw-Hill, New York. 
Spiegel E.F., Thompson P.M., Helden D.J., Doan H.V., Gaspar D.J. and Zanapalidou H., (1999) Investigation of an electrodeionization system for the removal of low concentrations of ammonium ions, Desalination, 123, 85-92.

Yang H., Zhang X. and Yuan W., (2008), ammonia removal from fertilizer plant effluents. Effect of Operating Parameters on the Condensation of Ammonium Sulfate by Electrodialysis, Chem. Eng. Technol., 31, 1261- 1264.

Zou L., Li L.,Song H., Morris G., (2008) Using mesoporous electrodes for brackish water desalination, Water Res., 42, 2340-2348. 